\title{
PERBEDAAN PERILAKU PROSOSIAL DITINJAU DARI JENIS KELAMIN
}

\author{
Jeanetha Anasthasia Elisabeth Lomboan \\ Fakultas Psikologi, Program Studi Psikologi, Universitas Kristen Satya Wacana \\ jeanethalomboan@gmail.com
}

\begin{abstract}
This study uses a comparative quantitative method that aims to find the difference in prosocial behavior based on sex in college students of Satya Wacana Christian University. There are 120 college students involved in this study as participants which consist of 60 men and 60 women. The sampling techniques in this study use the purposive sampling with the criteria of college students in their late adolescent, 18-22 years old, which actively involved in campus and participate in social activities more than three times in one year. The instruments that are used are arranged by the researcher based on aspects prosocial behavior. The result shows that there is no difference in prosocial behavior between male and female college students with a significance value $0 f=0,85$ ( $p$ $>0,05)$ so that the hypothesis in this study is rejected. Besides the sex factor, there are other factors that can influence someone to have prosocial behavior.
\end{abstract}

Keywords: late adolescent, prosocial behavior, sex.

\begin{abstract}
Abstrak
Penelitian ini menggunakan metode kuantitatif dengan jenis komparasi yang bertujuan untuk mengetahui perbedaan perilaku prososial ditinjau dari jenis kelamin pada mahasiswa Universitas Kristen Satya Wacana. Partisipan dalam penelitian ini melibatkan 120 mahasiswa yang terdiri dari 60 mahasiswa perempuan dan 60 mahasiswa laki-laki. Teknik sampling dalam penelitian ini menggunakan purposive sampling dengan kriteria partisipan remaja akhir usia 18-22 tahun yang sedang aktif mengikuti perkuliah dan sering mengikuti kegiatan sosial minimal tiga kali dalam setahun. Alat ukur yang digunakan disusun oleh peneliti berdasarkan aspek-aspek perilaku prososial. Hasil dalam penelitian ini menunjukkan bahwa tidak ada perbedaan perilaku prososial antara mahasiswa laki-laki dan mahasiswa perempuan dengan nilai signifikansi $=0,85(\mathrm{p}>0,05)$ sehingga hipotesis dalam penelitian ini ditolak. Selain faktor jenis kelamin, masih banyak faktor lain yang dapat mempengaruhi seseorang melakukan perilaku prososial.
\end{abstract}

Kata kunci: jenis kelamin, perilaku prososial, remaja akhir. 


\section{PENDAHULUAN}

Manusia adalah makhluk sosial yang tidak lepas dari orang lain. Dalam kehidupan sehari-hari manusia tidak dapat hidup sendiri dalam memenuhi kebutuhannya. Manusia diciptakan untuk saling berinteraksi dengan sesama serta mengembangkan sikap tolong menolong. Adanya rasa ketergantungan inilah yang kemudian menjadikan manusia mendapatkan label sebagai makhluk sosial (Walgito, 2003).

Seiring dengan berkembangnya zaman yang semakin modern membuat gaya hidup dan cara berperilaku individu mulai berubah. Sejak masuknya arus globalisasi dan didukung berkembangnya teknologi yang canggih membuat individu terkadang bersikap individualis. Salah satu contoh yaitu ketika individu dihadapkan dengan situasi untuk menolong orang lain, ada individu yang langsung membantu tetapi ada juga yang tidak bertindak atau memilih diam saja. Menurut Sears dkk. (1994) beberapa orang memberikan bantuan kepada orang lain meskipun dalam situasi yang tidak kondusif, tetapi masih ada orang yang tidak memberi bantuan meskipun berada dalam kondisi yang sangat baik.

Melihat situasi yang terjadi akhir-akhir ini perilaku prososial antar masyarakat mulai menurun. Dapat dilihat dari lingkungan sekitar kita saat ini sebagian besar orang tidak memperdulikan lingkungan sekitarnya. Hal tersebut didukung dengan berita-berita di surat kabar maupun di televisi tentang perampokan, pemerkosaan, tindakan kekerasan, penipuan dan perkelahian antar pelajar. Dari data badan pusat statistik selama periode tahun 2014-2016, jumlah kejadian kejahatan atau tindak kriminalitas di Indonesia cenderung meningkat. Jumlah orang yang terkena tindak kejahatan (crime rite) setiap 100 ribu penduduk diperkirakan sebanyak 131 orang pada tahun 2014, sedangkan pada tahun 2015 dan 2016 sebanyak 140 orang (Suhariyanto, 2017). Bintarto (1980) mengatakan bahwa modernisasi telah banyak memberi pengaruh terhadap kehidupan ekonomi, kehidupan sosial, kebudayaan, gaya hidup masyarakat Indonesia dan sebagainya.

Sebagai makhluk sosial kita harus menciptakan hal-hal yang membuat lingkungan sekitar kita menjadi harmonis seperti menghormati orang lain, menghargai orang lain, saling berbagi dan saling menolong atau yang disebut perilaku prososial. Perilaku prososial harus diajarkan sejak kecil agar anak dapat menanamkan nilai-nilai kebaikan dan dapat menjalin hubungan yang harmonis dengan lingkungan sekitarnya. Menurut Cholidah, Ancok, dan Haryanto (1996) perilaku prososial sangat penting untuk dilakukan bagi kesiapan seseorang dalam mengarungi kehidupan sosialnya. Dengan melakukan perilaku prososial seseorang akan lebih diterima dalam pergaulan dan kehadiran individu akan dirasakan lebih berarti. 
Menurut Bierhoff (2002) perilaku prososial adalah suatu tindakan yang dilakukan oleh si pemberi bantuan yang bermaksud untuk meningkatkan keadaan orang yang ditolong terlepas dari motif si pemberi bantuan, baik itu untuk mendapatkan pujian atau menghindari rasa bersalah. Sedangkan menurut Sears dkk. (1994) tingkah laku prososial merupakan tingkah laku yang menguntungkan orang lain. Tingkah laku prososial meliputi segala bentuk tindakan yang dilakukan atau direncanakan untuk menolong orang lain, tanpa memperhatikan motif si penolong.

Menurut Eisenberg dan Mussen (1989) perilaku prososial adalah tindakan sukarela dengan maksud membantu dan memberikan manfaat kepada orang lain. Aspek-aspek prososial yaitu: Berbagi (sharing), kerjasama (cooperative), menyumbang (donating), menolong (helping), kejujuran (honesty), dan kedermawanan (generosity).

Salah satu karakteristik individu yang dapat mempengaruhi perilaku prososial terhadap orang lain adalah jenis kelamin. Menurut Hungu (2007) seks atau jenis kelamin berkaitan dengan tubuh laki-laki dan perempuan, dimana laki-laki memproduksi sperma, sementara perempuan menghasilkan sel telur dan secara biologis mampu menstruasi, hamil dan menyusui. Perilaku prososial tidak timbul begitu saja melainkan dipengaruhi oleh beberapa faktor seperti bystander, daya tarik, atribusi terhadap korban, adanya pengaruh model, desakan waktu, sifat kebutuhan, empati, suasana hati, jenis kelamin dan sifat seseorang (Sarwono, 2002).

Berdasarkan faktor jenis kelamin Zahn-Waxler dan Smith (Renata \& Parmitasari 2016), mengatakan bahwa beberapa penelitian menunjukkan anak perempuan lebih banyak menunjukkan perilaku prososial dan empati terhadap orang lain dibandingkan anak laki-laki. Menurutnya dibandingkan anak laki-laki, anak perempuan lebih memiliki orientasi lebih besar terhadap kebutuhan dan kesejahteraan orang lain. Perempuan memiliki hormon esterogen yang mempengaruhi psikis dan perasaan sehingga menimbulkan empati terhadap sesuatu di luar dirinya sehingga empati dapat membangun kepedulian terhadap lingkungan sekitar (Suhardin, 2016). Pada jenis kelamin laki-laki mempunyai hormon testosteron yang membuat mereka lebih berani, senang akan tantangan, suka bersaing, beradu gagasan dan konsep (Amin, 2018).

Mahasiswa dianggap sebagai agen perubahan sehingga harus membawa nilai-nilai yang positif di lingkunganya. Mahasiswa yang sedang berada di perguruan tinggi biasanya berusia 18-22 tahun. Menurut Santrock (2003) usia 18-22 tahun dikategorikan berada pada tahap remaja akhir. Tugas perkembangan remaja akhir salah satunya yaitu harus mengembangkan konsep dan keterampilan intelektual yang sangat diperlukan untuk melakukan peran sebagai anggota masyarakat (Hurlock, 1991). Sebagai seorang mahasiswa harus mengembangkan dan 
menjunjung tinggi perilaku prososial dalam masyarakat.

Penulis melakukan wawancara pada tanggal 2 Juli 2018 dengan beberapa mahasiswa di Universitas Kristen Satya Wacana baik perempuan dan laki-laki tentang perilaku prososial yang pernah mereka lakukan. Dari hasil wawancara peneliti mendapatkan hasil bahwa mahasiswa laki-laki dan perempuan di Universitas Kristen Satya Wacana menunjukkan perilaku prososial melalui kegiatan kampus seperti donor darah, mengumpulkan baju untuk disumbangkan, menjadi relawan, kunjungan ke panti asuhan dan berbagi sembako kepada masyarakat. Intensitas perilaku prososial pada mahasiswa laki-laki menunjukkan bahwa ada beberapa mahasiswa yang mempunyai perilaku prososial yang tinggi dan dalam satu tahun terakhir mengikuti kegiatan lebih dari lima kali tetapi ada juga yang jarang melakukan perilaku prososial dengan intensitas di bawah dua kali. Sedangkan pada mahasiswa perempuan menunjukkan hasil yang sama yaitu terdapat beberapa mahasiswa yang memiliki intensitas yang tinggi tetapi ada juga yang memiliki perilaku prososial yang rendah. Alasan beberapa mahasiswa mempunyai perilaku prososial yang rendah yaitu kurangnya minat terhadap kegiatan sosial dan terkadang mereka lebih mementingkan urusan mereka sendiri.

Dari hasil penelitian yang dilakukan oleh Istiana (2018), Feinman (1978), dan Mestre dkk. (2009), perilaku prososial laki-laki lebih tinggi dibandingkan perempuan karena laki-laki lebih cepat dalam mengambil keputusan, mampu menghadapi situasi yang menantang dan mampu menghadapi resiko dari situasi dan bentuk pertolongan atau perilaku yang diberikan. Sedangkan perempuan masih ragu-ragu dalam berperilaku prososial karena ada rasa takut akan kejadian atau situasi, serta resiko dari yang ditimbulkan. Tetapi hal tersebut menjadi kontra dengan hasil penelitian Renata dan Parmitasari (2016), Kusumaningrum dan Dewi (2017), Abdullahi dan Kumar (2006), yang mendapatkan hasil bahwa perilaku prososial perempuan lebih tinggi dibandingkan laki-laki.

Berdasarkan fenomena yang telah dipaparkan dapat disimpulkan baik mahasiswa lakilaki dan perempuan di Universitas Kristen Satya Wacana melakukan perilaku prososial melalui kegiatan yang ada di kampus. Berdasarkan wawancara intensitas perilaku prososial baik mahasiswa laki-laki dan perempuan menunjukkan bahwa mahasiswa laki-laki dan perempuan ada yang memiliki intensitas yang tinggi dan ada juga yang memiliki intensitas yang rendah sehingga peneliti belum dapat menyimpulkan perilaku prososial yang lebih tinggi antara mahasiswa laki-laki dan perempuan. Tujuan penelitian ini adalah untuk mengetahui perbedaan perilaku prososial ditinjau dari jenis kelamin pada mahasiswa Universitas Kristen Satya Wacana. Manfaat secara praktis untuk memberikan masukan dan informasi tentang perbedaan 
perilaku prososial ditinjau dari latar belakang jenis kelamin sehingga dapat menjadi bahan evaluasi untuk pengembangan diri mahasiswa. Adapun hipotesis yang diajukan dalam penelitian ini yaitu ada perbedaan yang signifikan antara perilaku prososial ditinjau dari jenis kelamin pada mahasiswa Universitas Kristen Satya Wacana.

\section{METODE}

Pengumpulan data dalam penelitian ini menggunakan skala psikologi yang akan mengukur perilaku prososial. Alat ukur yang digunakan dalam penelitian ini berjumlah 56 aitem yang disusun oleh peneliti berdasarkan teori Eisenberg dan Mussen (1989), yang terdiri dari enam aspek yaitu berbagi (sharing), kerjasama (cooperative), menyumbang (donating), menolong (helping), kejujuran (honesty) dan kedermawanan (generosity). Sedangkan jenis kelamin dapat dilihat ketika partisipan mengisi kategori jenis kelamin pada skala yang disebar. Penelitian ini menggunakan try out terpakai, yaitu partisipan dalam try out terpakai sekaligus digunakan sebagai partisipan penelitian (Hadi, 2000).

Partisipan dalam penelitian ini yaitu mahasiswa Universitas Kristen Satya Wacana dengan kriteria partisipan yaitu mahasiswa aktif laki-laki dan perempuan usia 18-22 tahun dan sering mengikuti kegiatan sosial minimal tiga kali dalam setahun terakhir. Teknik sampling dalam penelitian ini menggunakan purposive sampling yaitu teknik penentuan sampel berdasarkan kriteria sampel yang sudah ditentukan (Sugiyono, 2007).

Peneliti menyebarkan skala melalui google form pada tanggal 22 Maret 2019. Setelah disebar melalui google form peneliti mendapatkan 126 tanggapan, kemudian peneliti menyeleksi partisipan yang sesuai dengan kriteria penelitian yaitu mahasiswa aktif dengan usia 18-22 tahun dan sering mengikuti kegiatan sosial minimal tiga kali dalam setahun terakhir. Setelah proses seleksi peneliti mendapatkan partisipan yang sesuai dengan kriteria berjumlah 60 orang mahasiswa perempuan dan 40 orang mahasiswa laki-laki. Alasan peneliti tidak mengambil 26 partisipan karena tidak memenuhi kriteria yaitu minimal mengikuti tiga kali kegiatan sosial dalam satu tahun terakhir.

Dari jumlah partisipan tersebut peneliti kemudian menyebarkan lagi skala prososial kepada mahasiswa laki-laki agar jumlah partisipan mahasiswa perempuan dan mahasiswa lakilaki menjadi seimbang. Peneliti menyebarkan angket di lingkungan kampus UKSW pada tanggal 27 Maret 2019, dengan bertanya secara langsung kepada mahasiswa laki-laki jika mahasiswa tersebut sesuai dengan kriteria partisipan penelitian maka mahasiswa dapat mengisi angket tersebut. Setelah disebar peneliti mendapatkan 20 partisipan mahasiswa laki-laki yang 
sesuai dengan kriteria, sehingga dalam penelitian ini peneliti mendapatkan 120 partisipan yaitu 60 perempuan dan 60 laki-laki.

\section{HASIL DAN PEMBAHASAN}

Setelah data terkumpul dilakukan uji daya diskriminasi dengan standar pengguguran 0,30. Menurut Azwar (2008) suatu item dengan validitas item $\geq 0,30$ maka item tersebut sudah dapat dikatakan memiliki daya diskriminasi yang baik. Setelah dilakukan uji daya diskriminasi terdapat 5 aitem yang gugur yaitu, aitem $5(0,198), 7(0,192), 9(0,251), 37(0,290)$ dan aitem $56(0,057)$. Kemudian dari 5 aitem yang gugur, dilakukan uji daya diskriminasi putaran kedua dan terdapat satu aitem yang gugur yaitu aitem nomor $2(0,298)$. Aitem-aitem yang dinyatakan memiliki daya diskriminasi yang baik berjumlah 50 aitem masing-masing aitem bergerak dikisaran 0,333-0,661 dengan reliabilitas 0,934.

Tabel 2.

Hasil Uji Normalitas

\begin{tabular}{llcc}
\hline Jumlah & Laki-Laki & Perempuan \\
& & \multicolumn{1}{c}{60} & \multicolumn{1}{c}{60} \\
\hline Parameter Normal & Rata-Rata & 164.2333 & 163.7000 \\
& Standar Deviasi & 16.57788 & 14.08124 \\
\hline Kolmogorov-Smimov Z & & 1.216 & .501 \\
\hline Asymp. Sig. (2-tailed) & & .104 & .963 \\
\hline
\end{tabular}

Berdasarkan uji normalitas pada variabel jenis kelamin laki-laki mempunyai nilai K-SZ sebesar 1.216 dengan nilai signifikasi 0,104 ( $\mathrm{p}>0,05)$ dan untuk nilai K-S-Z jenis kelamin perempuan yaitu 0,501 dan memiliki nilai signifikansi $0,963(\mathrm{p}>0,05)$. Hal ini menunjukkan bahwa dalam penelitian ini berdistribusi normal.

Tabel 3.

Uji Homogenitas

\begin{tabular}{ll}
\hline Prososial & \\
\hline Statistik Levene &. Sig \\
\hline 2.972 & .087 \\
\hline
\end{tabular}

Dari hasil uji homogenitas yang telah dilakukan menunjukkan koefisien Levene test sebesar 2.972 dengan signifikansi sebesar 0,087 dimana 0,087 >0,05 sehingga dapat disimpulkan data tersebut homogen. 
Dalam penelitian ini tingkat variabel prososial disusun menjadi lima kategori, yaitu: sangat tinggi, tinggi, sedang, rendah dan sangat rendah. Oleh karena itu terdapat sebanyak 50 aitem yang dinyatakan memiliki daya diskriminasi yang baik, maka interval yang digunakan adalah sebagai berikut:

Skor tertinggi $50 \times 4=200$

Skor terendah $50 \times 1=50$

Rumus Interval $\quad=\underline{\text { Skor tertinggi }- \text { skor terendah }}$

$$
=\underline{200-50}=30
$$

5

Berdasarkan hasil perhitungan di atas, berikut tabel kategorisasinya:

Tabel 4.

Kategorisasi Skor Perilaku Prososial Keseluruhan

\begin{tabular}{lccc}
\hline Kategori & Interval & $\mathrm{N}$ & Presentase \\
\hline Sangat tinggi & $170<\mathrm{x} \leq 200$ & 40 & $33 \%$ \\
Tinggi & $140<\mathrm{x} \leq 170$ & 76 & $63 \%$ \\
Sedang & $110<\mathrm{x} \leq 140$ & 4 & $4 \%$ \\
Rendah & $80<\mathrm{x} \leq 110$ & 0 & $0 \%$ \\
Sangat rendah & $50<\mathrm{x} \leq 80$ & 0 & $0 \%$ \\
\hline & $\sum$ & 120 & $100 \%$ \\
\hline
\end{tabular}

Tabel 4 menunjukkan bahwa kategori skor perilaku prososial secara keseluruhan terdapat $40(33 \%)$ mahasiswa baik laki-laki dan perempuan berada di kategori yang sangat tinggi dan pada kategori tinggi berjumlah 76 (63\%) orang. Sedangkan pada kategori sedang berjumlah 4 (4\%) orang. Skor minimum secara empiris yaitu 128 dan skor maksimum yaitu 197.

Tabel 5.

Kategori Skor Perilaku Prososial Laki-laki

\begin{tabular}{llll}
\hline Kategori & Interval & $\mathrm{N}$ & Presentase \\
\hline Sangat tinggi & $170<\mathrm{x} \leq 200$ & 20 & $33 \%$ \\
Tinggi & $140<\mathrm{x} \leq 170$ & 39 & $65 \%$ \\
Sedang & $110<\mathrm{x} \leq 140$ & 1 & $2 \%$ \\
Rendah & $80<\mathrm{x} \leq 110$ & 0 & 0 \\
Sangat rendah & $50<\mathrm{x} \leq 80$ & 0 & 0 \\
\hline & $\sum$ & 60 & $100 \%$ \\
\hline
\end{tabular}

Data pada tabel 5 menunjukkan bahwa 20 (33\%) mahasiswa laki-laki mempunyai perilaku prososial yang sangat tinggi dan 39 (20\%) mahasiswa laki-laki masuk dalam kategori tinggi. Selain itu pada kategori sedang berjumlah 1 (2\%) orang. Skor empiris yang diperoleh 
partisipan bergerak dari skor minimum 134 dan skor maksimum sebesar 196 dengan standar deviasi 16,57 dan nilai rata-rata 164,23 .

Tabel 6.

Kategori Skor Perilaku Prososial Perempuan

\begin{tabular}{llll}
\hline Kategori & Interval & $\mathrm{N}$ & Presentase \\
\hline Sangat tinggi & $170<\mathrm{x} \leq 200$ & 20 & $33 \%$ \\
Tinggi & $140<\mathrm{x} \leq 170$ & 37 & $62 \%$ \\
Sedang & $110<\mathrm{x} \leq 140$ & 3 & $5 \%$ \\
Rendah & $80<\mathrm{x} \leq 110$ & 0 & $0 \%$ \\
Sangat rendah & $50<\mathrm{x} \leq 80$ & 0 & $0 \%$ \\
\hline & $\sum$ & 60 & $100 \%$ \\
\hline
\end{tabular}

Tabel 6 menunjukkan bahwa kategorisasi perilaku prososial sangat tinggi berjumlah 20 (33\%) mahasiswa perempuan dan pada kategori tinggi berjumlah 37 (62\%) orang. Sedangkan pada kategori sedang berjumlah $3(5 \%)$ orang. Skor minimum secara empiris pada mahasiswa perempuan yaitu 128 dan skor maksimum 197 dengan standar deviasi 14,08 dan nilai rata-rata 163,70 .

Tabel 7.

Uji Sampel Independen

\begin{tabular}{|c|c|c|c|c|c|c|c|}
\hline & & $\mathrm{F}$ & Sig. & $\mathrm{df}$ & $\begin{array}{l}\text { Sig. (2- } \\
\text { tailed) }\end{array}$ & $\begin{array}{l}\text { Perbedaan } \\
\text { rata-rata }\end{array}$ & $\begin{array}{l}\text { Perbedaan } \\
\text { standar eror }\end{array}$ \\
\hline \multirow[t]{2}{*}{$\begin{array}{l}\text { Jenis } \\
\text { Kelamin }\end{array}$} & $\begin{array}{l}\text { Asumsi varian } \\
\text { yang sama }\end{array}$ & 2.972 & .087 .190 & 118 & .850 & .53333 & 2.80805 \\
\hline & $\begin{array}{l}\text { Asumsi varian } \\
\text { tidak sama }\end{array}$ & & .190 & 114.990 & .850 & .53333 & 2.80805 \\
\hline
\end{tabular}

Berdasarkan hasil dari tabel 7 menunjukkan bahwa uji sampel independen mempunyai nilai signifikansi yaitu $=0,85$ atau $\mathrm{p}>0,05$. Hal ini menunjukkan bahwa hipotesis dalam penelitian ini ditolak. Dengan demikian, tidak ada perbedaan perilaku prososial ditinjau dari jenis kelamin pada mahasiswa Universitas Kristen Satya Wacana. Hal ini selaras dengan yang dikemukakan oleh Mccoby dan Jacklin (1974), bahwa saat dilakukan pengukuran perilaku prososial yang aktual, hasilnya tidak terdapat perbedaan yang signifikan antara laki-laki dan perempuan. Selain itu, hasil penelitian ini juga mendapatkan hasil yang sama dengan penelitian yang dilakukan oleh Asih dan Pratiwi (2010), Fadhila dkk. (2004), dan Umayah dkk. (2018), bahwa tidak ada perbedaan antara perilaku prososial laki-laki dan perempuan. 


\section{SIMPULAN}

Berdasarkan hasil penelitian tentang perbedaan perilaku prososial mahasiswa laki-laki dan perempuan di Universitas Kristen Satya Wacana, didapatkan hasil perhitungan $=0,087$ dan nilai signifikansi $=0,85(\mathrm{p}>0,05)$. Oleh karena itu, hipotesis dalam penelitian ini ditolak. Hal ini menunjukkan bahwa tidak ada perbedaan perilaku prososial baik pada mahasiswa laki-laki maupun pada mahasiswa perempuan. Salah satu yang menjadi alasan hipotesis dalam penelitian ini ditolak yaitu Universitas Kristen Satya Wacana memberikan wadah kepada mahasiswa bukan hanya untuk mengembangkan kemampuan akademik tetapi juga mengembangkan keterampilan diri terutama dalam meningkatkan perilaku prososial terhadap lingkungan sekitar yaitu melalui kegiatan kemahasiswaan seperti bakti sosial, menjadi relawan dan pengabdian masyarakat. Hal inilah yang dapat membentuk perilaku mahasiswa agar dapat melakukan hal-hal yang positif saat berada di lingkungan masyarakat. Perilaku prososial yang paling banyak dilakukan mahasiswa laki-laki dan perempuan yaitu menyumbang barang, berbagi solusi kepada teman dan menjadi relawan.

Selain faktor jenis kelamin, masih banyak faktor yang dapat membuat orang melakukan perilaku prososial. Dari pendapat para ahli Sarwono (2002), menyimpulkan bahwa faktor yang memengaruhi perilaku prososial terbagi menjadi dua yaitu pengaruh situasional meliputi bystander, daya tarik, atribusi terhadap korban, adanya pengaruh model, desakan waktu dan sifat kebutuhan korban. Selain itu, faktor yang kedua yaitu pengaruh faktor dalam diri yang meliputi suasana hati (mood), sifat, tempat tinggal dan pola asuh dari orang tua.

Saran untuk penelitian selanjutnya, diharapkan memperhatikan setiap kalimat dalam aitem yang akan diukur sehingga tidak menjadi ambigu. Selain itu, disarankan untuk mengkaji faktor-faktor lain yang dapat mempengaruhi perilaku prososial.

Saran bagi mahasiswa, sebaiknya tetap menjaga perilaku prososial agar tetap tinggi dan memperbanyak mengikuti kegiatan sosial. Berdasarkan aitem yang gugur dapat dilihat mahasiswa masih takut dan ragu untuk menolong orang lain saat dalam kondisi darurat (kecelakaan lalu lintas) sehingga disarankan kepada mahasiswa untuk tidak takut ketika menolong orang dalam situasi yang tidak kondusif.

Orang tua diharapkan untuk menerapkan perilaku prososial dari kecil seperti membantu orang tanpa membedakan suku dan agama, menghormati orang lain dan tidak berperilaku curang, sehingga ketika anak tumbuh dewasa dapat membawa nilai-nilai yang baik di lingkungan masyarakat. Selain itu, anak dapat diikutsertakan dalam kegiatan kerohanian 
sehingga dari hal tersebut dapat membentuk pola pikir ke arah yang lebih baik dan terhindar dari perilaku negatif..

\section{DAFTAR PUSTAKA}

Abdullahi, I. A., \& Kumar, P. (2016). Gender differences in prosocial behaviour. The International Journal of Indian Psychology, 3(4), 171-175.

Amin, M. S. (2018). Perbedaan struktur otak dan perilaku belajar antara pria dan wanita; Eksplanasi dalam sudut pandang neuro sains dan filsafat. Jurnal Filsafat Indonesia, 1(1), 38-43.

Asih, G. Y., \& Pratiwi, M. M. S. (2010). Perilaku prososial ditinjau dari empati dan kematangan emosi. Jurnal Psikologi: Pitutur, 1(1), 33-42.

Azwar, S. (2008). Reliabilitas dan validitas. Yogyakarta: Pustaka Pelajar.

Bierhoff, H. W. (2002). Prosocial behaviour. New York: Psychology Press.

Bintarto. (1980). Gotong royong suatu karakteristik bangsa Indonesia. Yogyakarta: Bina Ilmu Surabaya.

Cholidah, L., Ancok, D., \& Haryanto. (1996). Hubungan kepadatan dan kesesakan dengan stres dan intensi prososial pada remaja di pemukiman padat. Jurnal Psikologika, 1(1), 56-64.

Eisenberg, N., \& Mussen, P. H. (1989). The roots of prosocial behavior in children. United Kingdom: Cambridge University Press.

Fadhila, A., Ekowarni, E., \& Purnamasari, A. (2004). Perbedaan intensi prososial siswa smun dan man di Yogyakarta. Humanitas: Jurnal Psikologi Indonesia, 1(1), 32-42.

Feinman, S., \& Gill, G. W. (1978). Sex differences in physical attractiveness preferences. The Journal of Social Psychology, 105(1), 43-52.

Hadi, S. (2000). Metodologi penelitian. Yogyakarta: Andi Yogyakarta.

Hungu. (2007). Demografi kesehatan Indonesia. Jakarta: Grasindo.

Hurlock, E. B. (1991). Psikolgi perkembangan suatu pendekatan sepanjang rentang kehidupan. Jakarta: Erlangga.

Istiana, I. (2018). Perbedaan perilaku prososial remaja ditinjau dari jenis kelamin di kelurahan Tanjung Rejo Medan Sunggal. Jurnal Diversita, 4(1), 58-67.

Kusumaningrum, E., \& Dewi, N. K. (2017). Perbedaan perilaku prososial dan self awareness terhadap nilai budaya lokal Jawa ditinjau dari jenis kelamin pada siswa sma kyai ageng basyariyah Kecamatan Dagangan Kabupaten Madiun. Counsellia: Jurnal Bimbingan dan Konseling, 6(2), 17-30. 
Maccoby, E. E., \& Jacklin, C. N. (1974). The psychology of sex differences. Stanford, CA: Stanford University Press.

Mestre, M. V., Samper, P., Frias, M. D., \& Tur, A. M. (2009). Are women more empathetic than men? A longitudinal study in adolescence. The Spanish Journal of Psychology, 12(1), 76-83.

Renata, S., \& Parmitasari, L. N. (2016). Perilaku prososial pada mahasiswa ditinjau dari jenis kelamin dan tipe kepribadian. Psikodimensia, 15(1), 24-39.

Santrock, J. W. (2003). Perkembangan remaja. Jakarta: Erlangga.

Sarwono, S. W. (2002). Psikologi sosial individu dan teori-teori psikologi sosial. Jakarta: Balai Pustaka.

Sears, D. O., Freedman., Jonathan, L., \& Peplau, L. A. (1994). Psikologi sosial (jilid 2). Jakarta: Erlangga.

Sugiyono. (2007). Metode penelitian kuantitatif kualitatif dan R\&D. Bandung: Alfabeta.

Suhardin, S. (2016). Pengaruh perbedaan jenis kelamin dan pengetahuan tentang konsep dasar ekologi terhadap kepedulian lingkungan. Edukasi Jurnal Penelitian Pendidikan Agama dan Keagamaan, 14(1), 117-132.

Suhariyanto. (2017). Crime statistics 2017. Jakarta: Badan Pusat Statistik.

Umayah, A. N., Ariyanto, A., \& Yustisia, W. (2018). Pengaruh empati emosional terhadap perilaku prososial yang dimoderasi oleh jenis kelamin pada mahasiswa. Jurnal Psikologi Sosial, 15(2), 72-83.

Walgito, B. (2003). Pengantar psikologi umum. Yogyakarta: Andi. 